\title{
Financial Constraints to SMME Growth: Investigating the Moderating Effect of Microfinance
}

\author{
Nasraldin Omer \\ Department of Accounting and Finance, College of Business Studies, \\ Sudan University of Science and Technology, Sudan, \\ nasraldein@gmail.com
}

Ricardo M. Peters

School of Business and Finance, Faculty of Economic and Management Sciences, University of the Western Cape, South Africa, rmpeters@uwc.ac.za

\section{Kobus Visser}

Faculty of Economic and Management Sciences, University of the Western Cape, South Africa, kvisser@uwc.ac.za

\begin{abstract}
Small, Medium and Micro Enterprises (SMME) play a significant role in an economy. SMMEs are an important source of jobs, entrepreneurial spirit and innovation. However, despite the noted contribution of SMMEs, in many countries they face serious constraints, often resulting in failure. The constraints and economic environment have significant and unequal effects on SMMEs in different industries and in different locations. Constraints have been used, amongst other growth factors, to understand why some SMMEs fail to grow. The aims of this study was to examine the effect of financial constraints on SMME growth and to investigate the moderating effect of microfinance on overcoming, avoiding or
\end{abstract}


mitigating the financial constraints to SMME growth. The study found evidence that the lack of professional financial advisors, lack of access to finance and lack of awareness of financial services and assistance were significant constraints to SMME growth in South Africa. However, beyond knowing the effects or constraints, it is important that entrepreneurs know how they can avoid constraints. The study shows that microfinance provides a way to overcome or mitigate financial constraints for SMMEs that exhibit a constraint to growth. These results imply that microfinance can play a positive role in SMME growth particularly for SMMEs that experience financial constraints. The study also suggests that MFIs and government agencies should provide more information to the public in particular to SMMEs so they can reduce the negative effect of lack of awareness of financial services and assistance on SMME growth.

KEYWORDS: SMME growth, financial constraints, microfinance, moderating effect, South Africa 